\title{
The International Society of Pharmacovigilance (ISoP) Pharmacogenomic Special Interest Group: Pharmacogenomics in Pharmacovigilance
}

\author{
Qun-Ying Yue ${ }^{1}$ (1)
}

Accepted: 30 March 2021 / Published online: 8 May 2021

(c) The Author(s) 2021

\section{Introduction}

There is wide variability between individual responses to drugs. This might be due to the heterogeneity of the treated disease and clinical variables of the patients, such as age, sex, diet, concomitant use of other drugs, and renal or hepatic functions. In addition, some of the variation in drug response is related to inherited characteristics of the genome. These genomic variations may relate to pharmacokinetics or pharmacodynamics, or to an individual's susceptibility.

The term pharmacogenetics has been used for about 6 decades, and is defined as the study of the variations in DNA sequence in each individual related to drug disposition (pharmacokinetics) or drug action (pharmacodynamics) that can influence their clinical response. In more recent years, the term pharmacogenomics has been introduced, and is defined more broadly as the application of genomic technologies to elucidate disease susceptibility, drug discovery, pharmacological function, drug disposition, and therapeutic response. Thus, pharmacogenomics describes the transition from genetics to genomics, and introduces a genome-wide approach to identify genes that contribute to a specific disease. In other circumstances, the two terms are used interchangeably.

There are a number of examples of the impact of pharmacogenomic variants. In relation to drug pharmacokinetics: codeine, tamoxifen and CYP2D6, clopidogrel and $C Y P 2 C 19$, fluorouracil, capecitabine and dihydropyrimidine dehydrogenase, and warfarin and $C Y P 2 C 9$; in relation to drug pharmacodynamics: VKORC1 polymorphisms and warfarin;

Qun-Ying Yue

qun-ying.yue@who-umc.org

1 International Society of Pharmacovigilance

Pharmacogenomic Special Interest Group, Uppsala

Monitoring Centre, Bredgränd 7, 75320 Uppsala, Sweden and in drug-induced toxicity risk status: $H L A-B * 5701$, and abacavir serious hypersensitivity [1-3].

The usefulness of genomic biomarkers has been demonstrated in different types of studies. First, abacavir, an antiretroviral drug used for treating human immunodeficiency virus infections, causes hypersensitivity syndrome in around $4 \%$ of the treated patients. The pharmacogenomic biomarker $H L A-B * 5701$ allele was shown in randomized clinical trials to strongly predict the occurrence of abacavirassociated hypersensitivity. Following the application of this biomarker, abacavir prescriptions increased and this biomarker might be one of the best examples of success where genotyping for one mutation can prevent the occurrence of an adverse drug reaction [4]. Mandatory screening for the $H L A-B^{*} 5701$ allele before starting abacavir therapy is now on the product label [5].

Another example of the usefulness of pharmacogenomic biomarkers in preventing adverse drug reactions through the selection of patients is testing for $H L A-B * 1502$ prior to starting carbamazepine and $H L A-B * 5801$ prior to starting allopurinol, and only using the drug in non-carriers. This has led to a lower risk of severe cutaneous adverse reactions of Stevens-Johnson syndrome and toxic epidermal necrolysis associated with these drugs $[6,7]$. It should be recalled that the biomarkers $H L A-B^{*} 1502$ and $H L A-B^{*} 5801$ are especially prevalent in some Asian populations, and that ethnicity matters [6-8].

Regarding genetic polymorphisms in drug-metabolizing enzymes, there are also some important examples of the current use of pharmacogenomic biomarkers in clinical practice. One of the recent examples includes eliglustat, a potent and specific inhibitor of glucosylceramide synthase, used for the long-term treatment of Gaucher disease. Before initiation of treatment, patients should be genotyped for CYP2D6 to determine the CYP2D6 metabolizer status. The target patient populations are indicated in $C Y P 2 D 6$ poor metabolizers, 
intermediate metabolizers, or extensive metabolizers, and also dosed according to the genotypes [9].

It has been shown that hospitalizations and emergency department visits can be reduced by genotyping elderly polypharmacy patients [10], and pre-prescription genotyping is cost effective for certain adverse drug reactions [11], although different results were observed in a recent retrospective study [12]. The International Society of Pharmacovigilance (ISoP) is an international non-profit scientific organization aiming to foster pharmacovigilance scientifically and educationally, and to enhance all aspects of the safe use of medicines, in all countries.

\section{Formation and Membership of the ISoP Pharmacogenomic (PGX) Special Interest Group (SIG)}

Against this background, in 2019, the ISoP Executive Committee encouraged the creation and development of a new SIG in ISoP dedicated to exploring issues related to pharmacovigilance relevant to medicines with pharmacogenomic associations, and on 5 May, 2020 approved the application for its establishment. The new SIG was launched at the online ISoP General Assembly in October 2020.

The members of this group have a specific interest in pharmacogenomics, with all levels of expertise or experience with pharmacogenomics, from those who work full time in the speciality, to those who want to learn more. What counts is a healthy interest in and enthusiasm for the topic and a willingness to contribute. As of February 2021, the PGx SIG comprised 16 members from nine countries in four continents.

The PGx SIG started its activities in the autumn of 2020 with monthly online meetings. The agenda usually consists of items such as round-table information exchange; sharing of relevant scientific publications, either of own research or other researchers; discussions on trends or new findings in the area, and possibilities for collaboration. One of the key objectives of the PGx SIG is to organize or contribute to training activities. In September 2020, a lecture on Pharmacogenomics in Pharmacovigilance was delivered during the ISoP Patient Safety Day.

\section{PGx SIG: Aims and Objectives}

The overall aim of the Pharmacogenomics SIG is to provide an opportunity for ISoP members interested in pharmacogenomics to share and provide information on relevant issues and developments; and to support pharmacovigilance relevant to medicinal products with pharmacogenomic associations.
The key objectives are:

1. To create networking opportunities for those researching and investigating pharmacogenomics, and to encourage collaboration and regularly share news and information to the pharmacogenomics SIG members, to expand knowledge of how medicines cause adverse reactions in genomic subpopulations and why efficacy may also be different.

2. To exchange experiences and provide support to healthcare professionals and/or organizations on the evaluation of pharmacovigilance related issues associated with pharmacogenomic biomarkers.

3. To organise and/or support training and tutorials for pharmacovigilance centers to increase understanding while focussing on aspects of pharmacovigilance and risk minimization measures relevant to medicinal products with pharmacogenomic associations. Insights from this can improve the benefit-risk balance in genomic subpopulations, and lead to better and more original study designs.

4. To organize, where possible, a session at the ISoP annual meeting on the topic of pharmacogenomics in pharmacovigilance.

5. To advise the ISoP Executive Committee, where required, on issues relating to pharmacogenomics in pharmacovigilance.

\section{Limitations and Challenges in Pharmacogenomics}

One of the major limitations that has prevented the use of pharmacogenomic testing in the clinical setting is the lack of prospective clinical trials for many drugs demonstrating the usefulness of pharmacogenomic biomarkers in assisting in the drug selection and dose for the individual patient to reach an optimal therapeutic response. The extent to which genetic factors contribute to the drug response or toxicity phenotype will not only depend on the gene effect (major, moderate, or minor), but also on non-genetic factors such as drug-drug interactions.

Another limitation is the insufficient predictability of the pharmacogenomic biomarker test for recommending genotype-guided dosing, e.g. for warfarin. Genetic variants in VKORC1 and CYP2C 9 have been shown to be associated with warfarin dose requirements. However, randomized clinical trials have not clearly shown the advantages of preemptive genetic testing.

A drug response involves several genes, and combining information from each of the contributing genes is expected to improve the predictive values of pharmacogenomic testing. Although the clinical utility of implementing a panel of 
PGx markers into routine care in Europe is yet to be established [13], there is active research in this area.

The new PGx SIG at the ISoP will contribute to the goal of identifying patients at risk and to improve the benefit-risk balance of drug treatment in genomic sub-populations.

The ISoP members with interest in pharmacogenomics are encouraged and warmly invited to join the PGx SIG.

At present, the PGx SIG is still in its early days. Current members of ISoP with an interest in pharmacogenomics are eligible to join. Those who would like to, or have questions, should contact ISoP Administration by e-mail (administration@isoponline.org).

Acknowledgements Deidre McCarthy and Mira Harrison-Woolrych conceived the idea for the series of articles of which this is one.

\section{Declarations}

Funding No sources of funding were used to prepare this article.

Conflict of interest Qun-Ying Yue has no conflicts of interest that are directly relevant to the content of this article.

Ethics approval Not applicable.

Consent to participate Not applicable.

Consent for publication Not applicable.

Availability of data and material Not applicable.

Code availability Not applicable.

Authors' contributions Qun-Ying Yue wrote this article in its entirety and read and approved the final version.

Open Access This article is licensed under a Creative Commons Attribution-NonCommercial 4.0 International License, which permits any non-commercial use, sharing, adaptation, distribution and reproduction in any medium or format, as long as you give appropriate credit to the original author(s) and the source, provide a link to the Creative Commons licence, and indicate if changes were made. The images or other third party material in this article are included in the article's Creative Commons licence, unless indicated otherwise in a credit line to the material. If material is not included in the article's Creative Commons licence and your intended use is not permitted by statutory regulation or exceeds the permitted use, you will need to obtain permission directly from the copyright holder. To view a copy of this licence, visit http://creativecommons.org/licenses/by-nc/4.0/.

\section{References}

1. Carr DF, Pirmohamed M. Biomarkers of adverse drug reactions. Exp Biol Med (Maywood). 2018;243(3):291-9.

2. European Medicines Agency. Fluorouracil and fluorouracil related substances (capecitabine, tegafur and flucytosine) containing medicinal products. https://www.ema.europa.eu/en/medicines/ human/referrals/fluorouracil-fluorouracil-related-substancescapecitabine-tegafur-flucytosine-containing-medicinal. Accessed 23 Feb 2021.

3. Lauschke VM, Milani L, Ingelman-Sundberg M. Pharmacogenomic biomarkers for improved drug therapy: recent progress and future developments. AAPS J. 2018;20(1):4.

4. Mallal S, Phillips E, Carosi G, Molina J-M, Workman C, Tomažič J, et al. HLA-B*5701 screening for hypersensitivity to abacavir. N Engl J Med. 2008;358(6):568-79.

5. emc. Ziagen $300 \mathrm{mg}$ film-coated tablets: summary of product characteristics (SmPC). https://www.medicines.org.uk/emc/produ ct/5518/smpc. Accessed 23 Feb 2021.

6. Chen P, Lin J-J, Lu C-S, Ong C-T, Hsieh PF, Yang C-C, et al. Carbamazepine-induced toxic effects and HLA-B*1502 screening in Taiwan. N Engl J Med. 2011;364(12):1126-33.

7. Ko T-M, Tsai C-Y, Chen S-Y, Chen K-S, Yu K-H, Chu C-S, et al. Use of HLA-B*58:01 genotyping to prevent allopurinol induced severe cutaneous adverse reactions in Taiwan: national prospective cohort study. BMJ. 2015;23(351):h4848.

8. Lonjou C, Thomas L, Borot N, Ledger N, de Toma C, LeLouet $\mathrm{H}$, et al. A marker for Stevens-Johnson syndrome .... ethnicity matters. Pharmacogenom J. 2006;6(4):265-8.

9. emc. Cerdelga $84 \mathrm{mg}$ hard capsules: summary of product characteristics (SmPC). https://www.medicines.org.uk/emc/product/ 2615/smpc. Accessed 24 Feb 2021.

10. Elliott LS, Henderson JC, Neradilek MB, Moyer NA, Ashcraft KC, Thirumaran RK. Clinical impact of pharmacogenetic profiling with a clinical decision support tool in polypharmacy home health patients: a prospective pilot randomized controlled trial. PLoS One. 2017;12(2):e0170905.

11. Collins SL, Carr DF, Pirmohamed M. Advances in the pharmacogenomics of adverse drug reactions. Drug Saf. 2016;39(1):15-27.

12. Takahashi PY, Ryu E, Bielinski SJ, Hathcock M, Jenkins GD, Cerhan JR, et al. No association between pharmacogenomics variants and hospital and emergency department utilization: a Mayo Clinic Biobank retrospective study. Pharmacogenom Personal Med. 2021;14:229-37.

13. van der Wouden C, Cambon-Thomsen A, Cecchin E, Cheung K, Dávila-Fajardo C, Deneer V, et al. Implementing pharmacogenomics in Europe: design and implementation strategy of the Ubiquitous Pharmacogenomics Consortium. Clin Pharmacol Ther. 2017;101(3):341-58. 